\title{
Genregulation
}

\section{So schadet Rauchen dem Fötus}

\section{Hier steht eine Anzeige.}

Rauchen in der Schwangerschaft führt beim Ungeborenen zu genomweiten epigenetischen Veränderungen - mit Folgen weit nach der Geburt. Solche Modifikationen können nämlich Kinder anfällig für Erkrankungen wie Asthma machen, legen Daten aus zwei Studien nahe.

Bei epigenetischen Veränderungen handelt es sich um das Anheften oder Entfernen von chemischen Gruppen u.a. an bestimmten Genbausteinen oder an Histonmolekülen. Dadurch wird die Expression von Genen an oder abgeschaltet, ohne den Genotyp zu verändern. Forscher um Dr. Irina Lehmann vom Helmholtz Zentrum für Umweltforschung (UFZ) in Leipzig konten zeigen, dass epigenetische Veränderungen durch das Rauchen sowohl bei den Müttern als auch im Nabelschnurblut der Neugeborenen nachweisbar sind.

\section{Rauchen beeinflusst regulatorische DNA-Regionen}

Ein Beispiel für eine solche Veränderung durch das Rauchen sei die Demethylierung eines sogenannten Enhancers für das Gen JNK2 (c-Jun N-terminal proteinkinase 2), ein regulatorisches Element der DNA, berichtete Lehmann auf einer Veranstaltung des Deutschen Krebsforschungszentrums (DKFZ) in Heidelberg. Dieses Gen ist Teil einer Signalkaskade, die für eine ganze Reihe von Lungenkrankheiten durch Rauchen von Bedeutung ist, etwa COPD und Lungenkrebs. Nach Angaben der Wissenschaftlerin ist von JNK2 bekannt, dass es an der Entstehung von Entzündungsreaktionen beteiligt ist und eine Rolle bei der Entwicklung von Asthma spielt. So sei die Demethylierung des JNK2-Enhancers mit dem Auftreten von Lungenerkrankungen in der frühen Kindheit assoziiert.

Die Auswertung der Mutter-Kind-Kohortenstudie LINA, in der die Methylierung des Enhancers im Nabelschnurblut bestimmt wurde, hat ergeben, dass die Wahrscheinlichkeit für den Asthmarisikofaktor Wheezing (Giemen) je 10\% Methylierungsverlust um 39\% steigt (adjustierte Odds Ratio [OR]: 1,39). Mit einer OR von 1,46 wurde in der Validierungsstudie LISA ein ähnlicher Wert ermittelt. Aus der LINA-Studie ging zudem hervor, dass die epigenetischen Veränderungen bei den Kindern jahrelang stabil blieben. Das Methylierungsmuster unterschied sich zwischen Geburt und erstem sowie dem vierten Lebensjahr kaum.

Peter Leiner

Mol Syst Biol. 2016; 12: 861,

DOl: $10.15252 / m s b .20156520$ 